\title{
An overview of the HIV prevention landscape in Zimbabwe: Implications for tenofovir gel
}

Population Council

Follow this and additional works at: https://knowledgecommons.popcouncil.org/departments_sbsr-hiv

Part of the Demography, Population, and Ecology Commons, Family, Life Course, and Society Commons, and the International Public Health Commons How does access to this work benefit you? Let us know!

\section{Recommended Citation}

Population Council. 2014. "An overview of the HIV prevention landscape in Zimbabwe: Implications for tenofovir gel." New York and Johannesburg: Population Council. 



\section{AN OVERVIEW OF THE HIV PREVENTION LANDSCAPE IN ZIMBABWE: IMPLICATIONS FOR TENOFOVIR GEL}




\section{ACKNOWLEDGMENTS}

This publication was prepared by Barbara Friedland, Samukeliso Dube, Martha Brady, Elizabeth McGrory, Saiqa Mullick, and Ravikanthi Rapiti. The authors would like to thank Joyce Altman for copyediting, Sherry Hutchinson for design assistance, and Virginia Kallianes for administrative support.

This activity was made possible by the generous support of the American people through the United States Agency for International Development (USAID). The contents are the sole responsibility of the Population Council and do not necessarily reflect the views of USAID or the United States Government.

POPULATION
COUNCIL

The Population Council confronts critical health and development issues-from stopping the spread of HIV to improving reproductive health and ensuring that young people lead full and productive lives. Through biomedical, social science, and public health research in 50 countries, we work with our partners to deliver solutions that lead to more effective policies, programs, and technologies that improve lives around the world. Established in 1952 and headquartered in New York, the Council is a nongovernmental, nonprofit organization governed by an international board of trustees.

One Dag Hammarskjold Plaza

New York, New York 10017 USA

Tel: 1-212-339-0500/Fax: 1-212-755-6052

www.popcouncil.org

Suggested citation: Population Council. 2014. "An overview of the HIV prevention landscape in Zimbabwe: Implications for tenofovir gel.” New York and Johannesburg: Population Council.

(C)2014 The Population Council, Inc.

Any part of this publication may be photocopied without permission from the publisher provided that copies are distributed without charge and that full source citation is provided. The Population Council would appreciate receiving a copy of any materials in which the text is used. 


\section{Table of Contents}

ACRONYMS i

$\begin{array}{ll}\text { PREFACE } & 1\end{array}$

$\begin{array}{ll}\text { INTRODUCTION } & 2\end{array}$

HIV EPIDEMIOLOGY IN ZIMBABWE 3

HIV Prevalence in Adults (15-49) by Age and Sex 4

HIV Prevalence in Pregnant Women 4

HIV in Young People Aged 15-24 5

HIV in Children under 15 Years 5

Variations in HIV Prevalence by Region and Socioeconomic Characteristics 6

$\begin{array}{ll}\text { Most at-Risk Populations } & 7\end{array}$

Vulnerabilities $\quad 8$

REPRODUCTIVE HEALTH 11

Sexual Debut $\quad 11$

Contraception and Fertility 11

Family Planning: Commodities and User Fees 11

Maternal and Child Health 12

Sexually Transmitted Infections and HIV 13

Cervical Cancer 14

POLICY RESPONSE

Programme Strategy and Implementation 16

Legal Frameworks and Context 17

$\begin{array}{ll}\text { Policies that Can Make a Difference } & 17\end{array}$

$\begin{array}{ll}\text { HIV PREVENTION } & 19\end{array}$

Knowledge about HIV and AIDS 19

HIV Testing 19

Male Condoms: Distribution and Use $\quad 21$

Female Condom Availability 22

Prevention of Mother-to-Child Transmission (PMTCT) 22

Male Circumcision 23

$\begin{array}{ll}\text { Post-Exposure Prophylaxis } & 23\end{array}$

HIV TREATMENT 
HEALTH SYSTEMS/SERVICE DELIVERY

HIV EXPENDITURE IN ZIMBABWE

LOOKING AHEAD

27

REFERENCES 


\section{ACRONYMS}

\begin{tabular}{|c|c|}
\hline AIDS & Acquired immunodeficiency syndrome \\
\hline ANC & Antenatal care \\
\hline ARV & Antiretroviral \\
\hline ART & Antiretroviral therapy \\
\hline CDC & Centers for Disease Control and Prevention \\
\hline CPT & Cotrimoxazole preventative therapy \\
\hline DTTU & Delivery Team Top Up \\
\hline GoZ & Government of Zimbabwe \\
\hline HIV & Human immunodeficiency virus \\
\hline HTC & HIV testing and counselling \\
\hline IDU & Injection drug user \\
\hline IOM & International Organization for Migration \\
\hline MARPs & Most at-risk populations \\
\hline MC & Male circumcision \\
\hline MDG & Millennium Development Goal \\
\hline MMR & Maternal mortality rate \\
\hline MoHCW & Ministry of Health and Child Welfare \\
\hline MSM & Men who have sex with men \\
\hline NAC & National AIDS Council \\
\hline NGO & Non-governmental organisation \\
\hline PCR & Polymerase chain reaction \\
\hline PEP & Post-exposure prevention \\
\hline
\end{tabular}




$\begin{array}{ll}\text { PEPFAR } & \text { U.S. President's Emergency Plan for AIDS Relief } \\ \text { PICT } & \text { Provider initiated counselling and testing } \\ \text { PLHIV } & \text { People living with HIV } \\ \text { PMTCT } & \text { Prevention of mother-to-child transmission } \\ \text { PSI } & \text { Population Services International } \\ \text { STI } & \text { Sexually transmitted infection } \\ \text { UNAIDS } & \text { Joint United Nations Programmes on HIV and AIDS } \\ \text { UNFPA } & \text { United Nations Population Fund } \\ \text { UNICEF } & \text { United Nations Children's Fund } \\ \text { USAID } & \text { United States Agency for International Development } \\ \text { VCT } & \text { Zoluntary counselling and testing } \\ \text { ZIMFPC } & \text { Zimbabwe National Family Planning Council } \\ \text { ZIA } & \text { Visual inspection using acetic acid } \\ \text { VMMC } & \text { Voluntary medical male circumcision } \\ \text { WHO } & \text { World Health Organisation } \\ \text { ZAmbabwe Demographic and Health Survey }\end{array}$




\section{PREFACE}

Zimbabwe, like many other African countries, has seen a tremendous shift in the HIV landscape in the last decade, particularly with respect to HIV prevalence (Hargrove et al. 2011). This shift parallels global efforts to reduce incidence of HIV, especially among the most vulnerable populations. Local strategies to reduce the impact of HIV have included scaling up treatment access and HIV prevention programmes, with an emphasis on behavioural interventions such as increased condom use and reduction of sexual partners. These efforts are notable and have made important contributions to reducing infections. Yet many people, especially women, are still at high risk and efforts to identify and implement additional HIV prevention options remain critical.

Topical microbicides are a promising new technology that women could control or initiate, with a number of products tested in clinical trials over the past two decades. Zimbabwe has played a key role in microbicide research, having participated in many large-scale safety and effectiveness trials of candidate products, including Pro2000, Buffergel, and tenofovir gel. Tenofovir gel is the product furthest along in development after the CAPRISA 004 trial in South Africa demonstrated a 39 percent HIV risk reduction among women in the tenofovir gel arm compared with those in the placebo arm (Abdool Karim et al. 2010). A confirmatory trial of tenofovir gel, FACTS 001, is currently underway in South Africa with results expected in late 2014.

As research moves forward, decision-makers and other stakeholders need key background information to inform strategic decision-making regarding introduction of tenofovir gel and other new HIV prevention products. A number of efforts are underway to develop and compile this information. To that end, the Population Council has designed a toolkit to assist policy makers and programme managers in identifying strategic opportunities for introducing tenofovir gel, "A Toolkit for Strategic Decision-making and Planning for Microbicides” (Population Council 2012). The toolkit consists of three related modules: 1) a landscape analysis; 2 ) a discussion guide for key opinion leaders; and 3) a programme planning guide.

As part of a process to test the toolkit, a landscape analysis (module 1) was undertaken in preparation for interviews with key opinion leaders (module 2) in Zimbabwe (Population Council 2014; Dube et al. 2013). As designed in the toolkit, this landscape analysis drew on a desk review of peer-reviewed and grey literature to:

Describe the epidemiology of HIV in Zimbabwe;

- Describe services related to HIV prevention and treatment to contextualise possible product introduction channels and platforms; and

- Provide an overview of the policy environment in Zimbabwe, including opportunities for new product introduction in the context of HIV prevention. 


\section{INTRODUCTION}

\section{Overview of HIV services in}

Zimbabwe: 2012

- Among pregnant women who were tested for HIV at all facilities, 14 percent tested HIV positive. The majority (94 percent) of women who tested HIV positive started antiretroviral (ARV) prophylaxis to prevent transmission and 30 percent started antiretroviral therapy (ART).

- Almost all (98 percent) primary care (Level 1) facilities offer STI diagnosis and treatment services, with half of them routinely charging a fee for these services.

> 96 percent of Level 1 facilities offer provider initiated counselling and testing (PICT).

- 79 percent of facilities offer early infant diagnosis using dried blood spots for DNA polymerase chain reaction (PCR) testing.

$\checkmark 89$ percent of Level 1 facilities routinely screen TB patients for HIV.

- More than 90 percent of hospitals reported providing both adult and paediatric ART initiation and follow-up services.

- No Level 1 facilities in Harare or Bulawayo initiated children on ART, and significantly fewer Level 1 facilities in Harare and Bulawayo offered paediatric ART follow-up services than in other provinces.

- 91 percent of Level 1 facilities offered HIV antibody testing.

- The majority of health workers (72 percent) in Level 1 services screened for HIV in the initial assessment.

Source: National Integrated Health Facility Assessment Report, completed October 2012
Zimbabwe is recovering from unprecedented socio-economic decline, which has significantly compromised the availability, use, and quality of health and social services. As a result, there has been a systematic decrease in coverage of most basic health services, leading to stagnation or deterioration of some health indicators. During this time, HIV was a significant factor contributing to the burden of disease (Gregson et al. 2010; Munjoma et al. 2010).

Despite the decay in health services and indicators, Zimbabwe is on track to achieve Millennium Development Goal (MDG) Number 6halting and reversing the spread of HIV/AIDS by 2015 (United Nations 2014). The decrease in HIV prevalence from 20 percent in 2005 to less than 15 percent in 2012 (UNAIDS 2013) can be attributed to both high mortality rates and changes in sexual behaviour. Although Zimbabwe is one of the few countries in the region to have experienced a substantial reduction in HIV prevalence, HIV/AIDS continues to be a significant public health problem (Halperin et al. 2011; Gregson et al. 2010).

UNAIDS reports that both the Ministry of Health and Child Welfare (MoHCW) and the National AIDS Council (NAC) have shown strong leadership in programming for HIV/AIDS and tuberculosis (TB) (UNAIDS 2012). Support for these programmes currently comes from several international and national sources, including the Global Fund, the US President's Emergency Plan for AIDS Relief (PEPFAR), other donor support to specific non-governmental organizations (NGOs). Zimbabwe's public/ private partnerships have successfully led to scaling up programmes for prevention of mother-to-child transmission (PMTCT) and voluntary medical male circumcision (VMMC), which can provide lessons for the introduction of tenofovir gel and other ARV-based prevention for women. 


\section{HIV EPIDEMIOLOGY IN ZIMBABWE}

Zimbabwe is one of the countries hardest hit by the HIV epidemic. With nearly 10 percent of the estimated population of 12.7 million people infected with HIV, Zimbabwe has the third largest HIV burden in southern Africa (Fraser et al. 2011). Zimbabwe's epidemic is considered to be generalised, with heterosexual transmission accounting for 92 percent of all HIV infections (ZIMSTAT and ICF International 2012). HIV and AIDS affects women disproportionately, as women comprise 62 percent of people living with HIV (PLHIV) in Zimbabwe and vertical transmission, where HIV is passed from a mother to her child during pregnancy, childbirth, and breastfeeding, is the second most common mode of transmission (Fraser et al. 2011).

HIV incidence had declined from a peak in the mid-1980s to less than 1 percent in 2009 (Fraser et al. 2011). The number of deaths due to AIDS has also been decreasing, with an estimated 160,000 deaths in 2001 to 39,000 in 2012 (UNAIDS 2013). Despite declines in HIV prevalence, incidence, and mortality (Figure 2), a total of 1.2 million adults and children were living with HIV and AIDS in 2012, 69,000 of whom were newly infected, including 14.7 percent of the population 15-49 years old (UNAIDS 2013; ZIMSTAT 2012).

Figure 2. Trends in HIV incidence, prevalence, mortality in Zimbabwe, 1980-2010

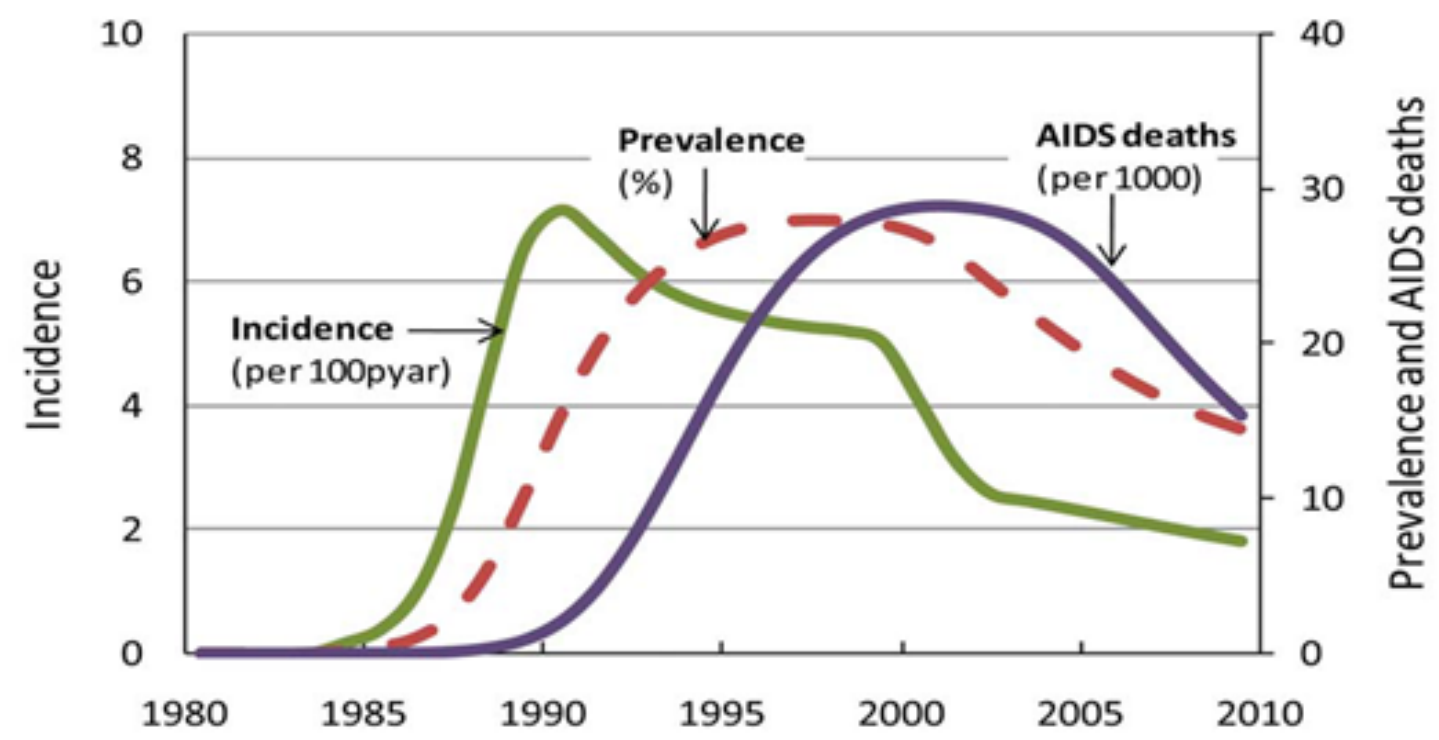

Source: Halperin et al. 2011. 


\section{HIV Prevalence in Adults (15-49) by Age and Sex}

According to the 2011-2012 Zimbabwe Demographic and Health Survey (ZDHS), HIV prevalence was 18 percent in women and 12 percent in men, overall with prevalence higher among women than men in every age group except ages 40-49 (ZIMSTAT 2012). In both males and females, prevalence is lowest in 15-19 year olds and increases with age, peaking at 29 percent among women 30-39 and at 30 percent among men 45-49, and declining thereafter. The most pronounced difference by age and gender is in the 20-29-year-old age group; prevalence is twice as high among females (11-20 percent) than males (4-10 percent) of the same age (Figure 3). HIV prevalence has declined since the previous DHS from 21 percent to 18 percent among women, 15 percent to 12 percent among men, and 18 percent to 15 percent overall, among 15-49 year olds (ZIMSTAT 2012).

Figure 3. HIV prevalence by age and sex in Zimbabwe (2010-2011)

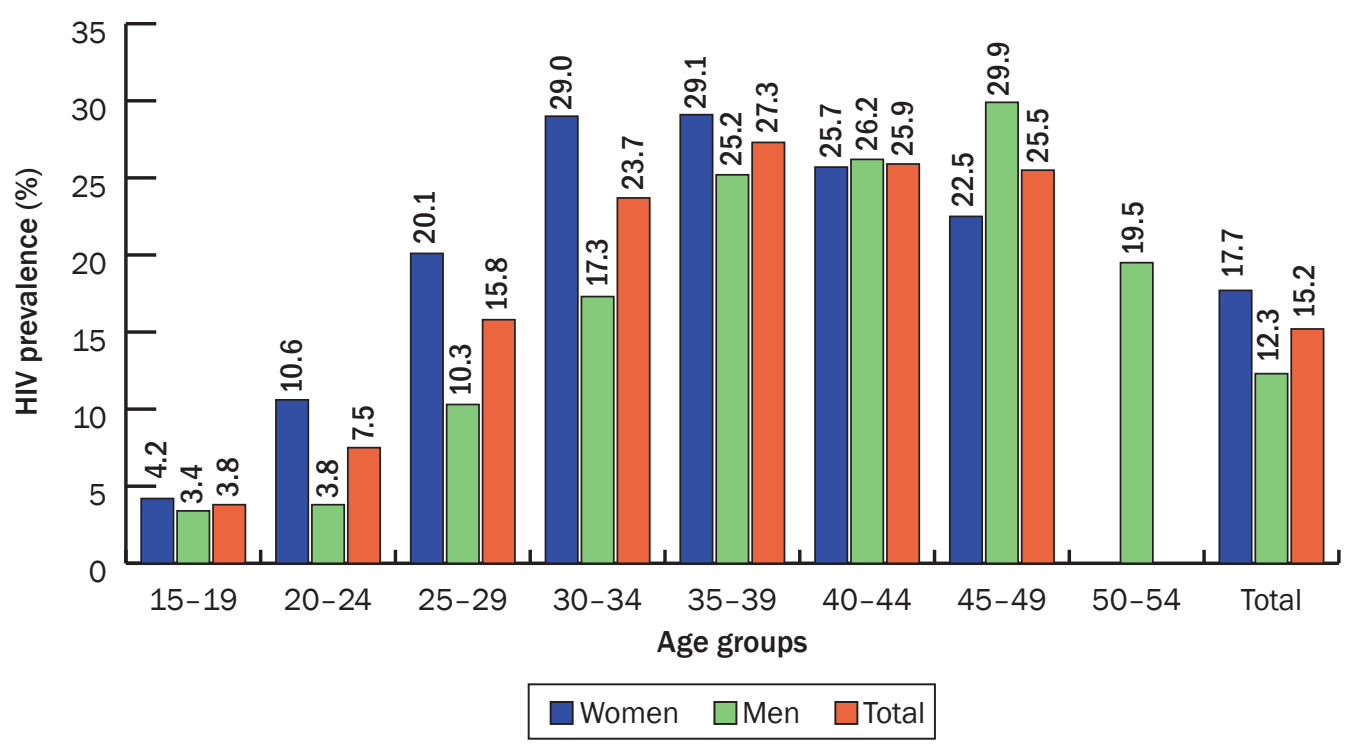

Source: ZIMSTAT and ICF International. 2012. ZDHS 2010-2011.

\section{HIV Prevalence in Pregnant Women}

Surveillance data from antenatal (ANC) facilities indicates that HIV prevalence is also declining among pregnant women (UNAIDS 2012). In 2009, prevalence among ANC attendees aged 15-49 was estimated to be 16 percent, down from 26 percent in 2002 (see Figure 4). A similar pattern of declining prevalence rates was also seen when looking specifically at the youngest women (aged 15-24 years old); whereas 21 percent of young ANC attendees were estimated to be infected with HIV in 2002, less than 12 percent were estimated to have been infected in 2009 (UNAIDS 2012). 
Figure 4. Trends in HIV prevalence among women 15-49 at ANC sentinel sites, by sentinel site (2002-2009)

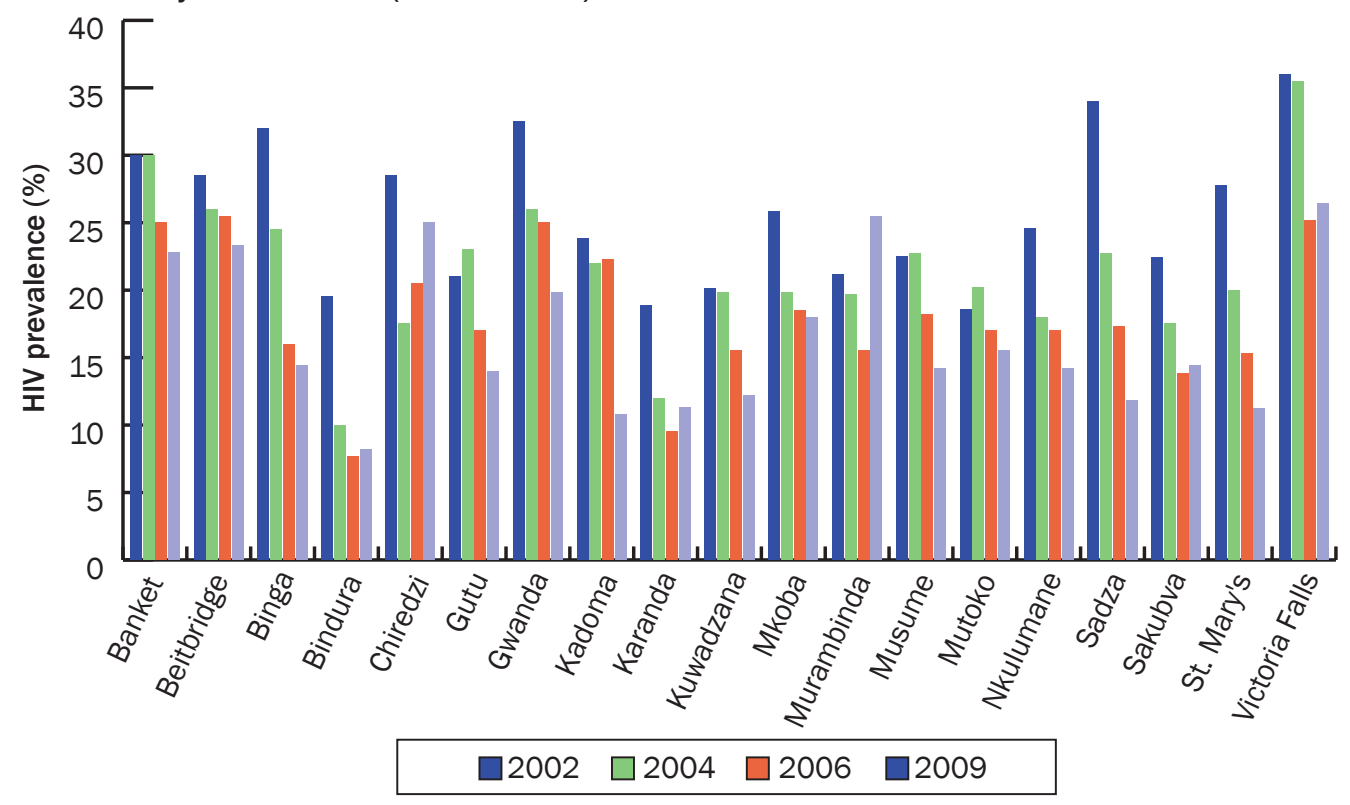

Source: ANC Sentinel Surveillance Reports, Ministry of Health and Child Welfare

\section{HIV in Young People Aged 15-24}

Data from the 2010-11 ZDHS revealed that overall 6 percent of respondents aged 15-24 (6.6 percent women and 3.4 percent men) were HIV positive and that young people living in urban areas are more likely to be infected than those in rural areas. While 6 percent of women and 2 percent of men reported having had sex by the age of 15 (ICF Macro 2011), sexual debut generally occurs relatively late in Zimbabwe, and there are no signs that the temporal trend of sexual debut has changed significantly. In youth aged 15-24 years, the frequency of reported premarital sex showed a modest decline over the four ZDHSs. Further, young women and young men with a history of a sexually transmitted infection (STI) or STI symptoms had higher rates of HIV infection than those with no symptoms (ICF Macro 2011). Individuals who had previously been tested for HIV were more likely to be HIV positive than those who had never been tested (21 percent and 15 percent, respectively).

\section{HIV in Children under 15 Years}

According to NAC, more than 500,000 children were born with HIV between 1980 and 2005, representing 5 percent of all births during those years (Fraser et al. 2011). The HIV prevalence among children under 15 years of age has also been declining, primarily due to lower rates of HIV among pregnant women, as well as success in programmes for PMTCT. Vertical transmission peaked at nearly 10 percent in the mid-1990s and decreased to 6 percent in 2005. In 2012, the number of children under 15 years of age acquiring HIV was 9,300, representing only one-quarter the number of new infections $(37,000)$ occurring in 2001 (UNAIDS 2013). 


\section{Variations in HIV Prevalence by Region and Socioeconomic Characteristics}

Since the last ZDHS, HIV prevalence rates have become more disparate between provinces (see Figure 5). In Harare, for example, prevalence was over 19 percent in 2005-2006, which was similar to most other provinces at the time (Fraser et al. 2011). In 2010-2011, however, Harare's prevalence had decreased substantially to just over 13 percent, whereas prevalence in Matabeleland South had risen to over 21 percent (NAC 2010; ZIMSTAT 2012). HIV prevalence was also slightly higher in urban (16.7 percent) than rural (14.6 percent) areas (ZIMSTAT/ICF International 2012). According to the 2010-2011 ZDHS, prevalence was higher among those who were employed (17.0 percent) than those who were unemployed (13.1 percent), which was the case for both men (13.8 percent vs. 9.1 percent) and women (21.4 percent vs. 15.0 percent). For men, HIV prevalence was associated with both education and wealth, with rates of HIV decreasing as level of education and wealth increased. Among women, the relationship between HIV, education and wealth was less clear; however, women in the highest categories of education (having greater than a secondary education) and wealth (in the highest quintile) had the lowest (ZIMSTAT/ICF International 2012).

The 2010-2011 ZDHS also indicated an association between HIV prevalence and marital status, with the lowest rates among young people who had never married (5 percent among women, 3 percent among men) and the highest rates among men (21 percent) and women (16 percent) who were widowed, divorced or separated (ZIMSTAT/ICF International 2012). Marriage was protective for sexually active women, with 14 percent of those who had never been married being HIV positive compared to 8 percent of those currently married or living as married. For men, overall prevalence was lower with little difference between those who were married (4 percent) and never married (3 percent).

Figure 5. Adult HIV prevalence by province (2010-2011)

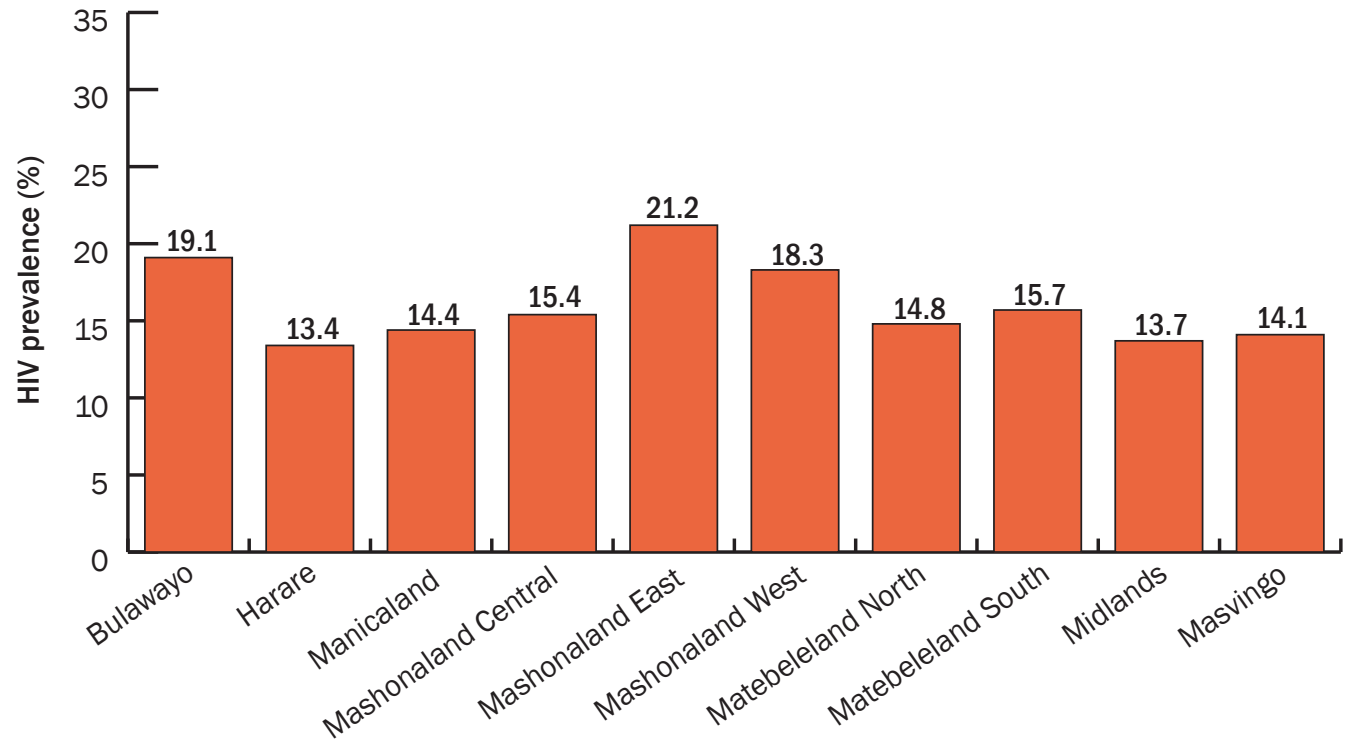

Source: ZIMSTAT and ICF International. 2012. ZDHS 2010-2011. 


\section{Most at-Risk Populations}

In Zimbabwe, data are scarce for sex workers, men who have sex with men (MSM) and injecting drug users (IDUs), defined as the "most at-risk populations" (MARPs) by UNAIDS. Little information is available about overall HIV prevalence in these populations, and to date no systematic size estimations have been undertaken. Because sex work and same-sex relations are illegal in Zimbabwe, combined with definitional and measurement problems, it is likely that both are underreported. Despite these challenges, some groups focused on HIV prevention have been successful in identifying "hot spots" and providing services to these groups, as described below.

\section{Sex workers}

Although sex work is illegal in Zimbabwe, the country has a sex-work industry and transactional relationships are common (Fraser et al. 2011). A recent study by Cowan et al. estimated HIV prevalence to be four times higher among sex workers than among women attending ANC clinics (Cowan et al. 2012). In addition, while HIV prevalence has declined significantly in the general population, Cowan's study indicated no change in prevalence among sex workers since 2001.

Several studies have sought to characterise sex work and sex workers. Using qualitative research in 12 sites, a 2008 situation and response analysis conducted by NAC, the International Organization for Migration (IOM), UNAIDS and UNFPA found that sex workers included girls as young as 12 years old up to women in their 60s (Fraser et al. 2011). Sex workers are highly mobile and may work along trucking routes or from entertainment establishments. The reported number of clients per day ranges from one to 12, and includes men from all over southern Africa from a variety of backgrounds.

Definitions vary with regard to what is considered "sex work" and what is considered "transactional sex," or sex in exchange for money or goods. In a 1997 sentinel survey, 20 percent of both male and female participants reported having had transactional sex in the past six months (Decosas and Padian 2002). Divorced, separated and widowed respondents reported higher rates of transactional sex (33 percent among men, 36 percent among women). Another study indicated that 17 percent of women attending family planning or primary care clinics in Harare reported ever having received a gift in exchange for sex (Decosas and Padian 2002).

According to the 2010-11 ZDHS (ZIMSTAT/ICF International 2012), men aged 25-49 (20-30 percent), men who had ever been married (25-35 percent), and men living in urban areas (20 percent) were most likely to have paid for sex; divorced, widowed, or separated men (6 percent) had the highest rate of paid sex during the 12 months preceding the survey. In terms of risk reduction, 88 percent of men who had engaged in paid sex in the past 12 months reported using a condom the last time. ZDHS data from 2005-06 and 2010-11 suggest essentially no changes in the percentage of Zimbabwean men who paid for sex. 
A 2008 situation analysis underscored that programmes for sex workers were limited and underfunded (UNAIDS 2012). Current sex worker interventions include HIV prevention education, risk-reduction counselling, condom distribution, STI treatment, peer education, microcredit and other measures that facilitate exit from sex work (Muchini et al. 2011). Reported condom use is inconsistent and was low in the late 1980s, however by 2007 had increased to approximately 72 percent among male clients using condoms at last sex act (Gregson et al. 2010). In a 2011 study commissioned by the Zimbabwe AIDS Prevention Project (ZAPP) to institute HIV prevention programmes, 68 percent of sex workers reported using a condom with their most recent client; nearly 60 percent of sex workers had received an HIV test in the past 12 months and knew their results; and 50 percent were living with HIV (UNAIDS 2011).

\section{Men who have sex with men}

According to several resources (Fraser et al. 2011; UNAIDS 2012; amFAR 2014), there is no reliable data on the population size or on HIV prevalence among MSM in Zimbabwe, largely due to considerable legal barriers and stigma at the highest levels of government (see below regarding laws on MSM and their implications).

\section{Injection drug users}

Although it is acknowledged that there is injection drug use and that it contributes to the HIV prevalence in Zimbabwe, according to the NAC no data are available on HIV prevalence in this population (Fraser et al. 2011).

\section{Vulnerabilities}

\section{Women, girls, and violence}

As in many other settings, young women's risk is driven by a complex array of biological, social, economic, and structural factors. Domestic violence is a widely acknowledged concern in Zimbabwe and, in response, the Domestic Violence Act was enacted in 2007 (Domestic Violence Act 2007). Despite the new legislation and efforts to address violence among women and vulnerable populations, much remains to be done. Reliable data are needed to inform policy and the public about the scope and nature of the problem. However, efforts to collect reliable data are hampered by varied perceptions and definitions of violence and abuse across cultures and individuals, and a "culture of silence" that affects reporting.

The 2010-11 ZDHS (ZIMSTAT/ICF International 2012) found that sexual and physical violence occurred in intimate and other relationships across culture and class, but wealthier and more empowered women and those in monogamous relationships experienced it less often. This same study provided a number of other insights into physical and sexual violence. Thirty percent of women aged 15-49 reported experiencing physical violence since the age of 15, and the most common perpetrator was her current or former husband or partner. In addition, 22 percent of women reported that their first sexual experience was forced. These data also indicate that 34 percent of men and 40 percent of women believe that a husband is justified in beating his wife. Only 37 percent of women who experienced physical or sexual violence 
have sought help. Domestic violence is also associated with HIV. Married women who had experienced physical violence only, or both physical and sexual violence, were significantly more likely to be HIV positive than those who had not experienced any physical or sexual violence (Nyamayemombe et al. 2010).

\section{Marriage and age disparity}

In comparison to many other countries in southern Africa, rates of marriage are higher in Zimbabwe (Fraser et al. 2011); as a result, the majority of PLHIV in Zimbabwe are married or living as married (74 percent of males and 58 percent of females). Of couples affected by HIV, 47 percent are discordant, where one partner is HIV negative and the other positive, which represents an important opportunity for prevention (Fraser et al. 2011).

Despite the high rates of marriage in Zimbabwe, expectations differ for men and women in terms of the appropriate age for marriage. Women are considered to be ready for marriage in their late teens, while men are expected to gain sexual experience with multiple partners prior to getting married in their mid- to late-twenties (Gregson et al. 2010; Singh et al. 2000; Decosas and Padian 2002). The different expectations for marriage are indicated in the 2010-11 ZDHS, which reported that 31 percent of married women versus 4 percent of married men aged 25-49 years were married by age18 (ZIMSTAT/ICF International 2012).

Age-disparate relationships have been associated with increased HIV prevalence, and older partners are a key determinant of the more rapid rise in HIV prevalence in young women than in young men. The 2010-11 ZDHS (ZIMSTAT/ICF International 2012) indicated that 15 percent of young women aged 15-19 who had sexual intercourse had sex with a man 10 or more years older.

\section{Alcohol use}

Men's alcohol use is associated with higher numbers of sexual partners, as well as with HIV infection and acquisition of HIV (Fraser et al. 2011). Data collected from women attending family planning or primary care clinics in Harare showed that 24 percent reported that their partner was intoxicated during sexual intercourse more than half the time (Decosas and Padian 2002). A study of the role of beer halls in the HIV epidemic found that men and women who had visited a beer hall reported higher numbers of lifetime sexual partners, partners in the last year, and new partners in the past year. Attendance at beer halls was also associated with concurrent sexual partnerships (Lewis et al. 2005). Men who report having sex while drunk have also been found to be more likely to report unprotected sex with casual partners and when paying for sex (Fraser et al. 2011).

\section{Multiple partners and concurrency}

Despite reports of behaviour change in the last decade, sex with high-risk partners (defined as non-marital or non-cohabiting partners) and multiple partners continues to be strongly associated with risk of HIV infection, particularly among women (Fraser et al. 2011). According to one study, having multiple partners in the past month was associated with almost nine 
times the rate of incident HIV infection among women compared to women who had only one partner (Fraser et al. 2011).

According to the 2010-2011 ZDHS, the likelihood of being HIV positive was much greater for men and women with higher numbers of lifetime partners. Whereas only 4 percent of men and 12 percent of women who had only one lifetime partner were HIV positive, 27 percent of men and more than 40 percent of women with more than three lifetime partners were HIV positive (ZIMSTAT/ICF International 2012).

\section{Tuberculosis and HIV co-infection}

HIV and TB are intricately linked; TB is the number one cause of death among HIV-infected people worldwide and HIV is the most important risk factor for TB. HIV-positive people have ten times greater risk of developing TB compared to those who are HIV uninfected (Republic of Zimbabwe 2010). In Zimbabwe, it is estimated that 80 percent of all TB cases are co-infected with HIV (Republic of Zimbabwe 2010).

Although an increasing number of patients have initiated cotrimoxazole preventative therapy (CPT) for TB and are referred for ART (see Table 1, below), there are a number of gaps in prevention, treatment and care for PLHIV co-infected with TB (Republic of Zimbabwe 2010).

Table 1: Testing, treatment and care for HIV and TB co-infection, 2008-2010

\begin{tabular}{|lllc|}
\hline Indicator & $\mathbf{2 0 0 8}$ & $\mathbf{2 0 0 9}$ & $\mathbf{2 0 1 0}$ \\
\hline \%/\# of TB cases tested for HIV & $45(18,310)$ & $76(35,886)$ & $88(40,714)$ \\
\%/\# of HIV-positive TB cases & $76(18,310)$ & $79(28,507)$ & $77(31,538)$ \\
\%/\# of HIV-positive TB cases put on CPT & $79(12,402)$ & $74(20,993)$ & $87(27,569)$ \\
$\begin{array}{l}\text { \%/\# of estimated HIV-positive incident TB } \\
\text { cases that received treatment for both TB }\end{array}$ & $10(4,630)$ & $18(8,658)$ & $23(13,999)$ \\
and HIV & & & \\
\hline
\end{tabular}

Source: UNAIDS 2012 


\section{REPRODUCTIVE HEALTH}

\section{Sexual Debut}

According to the 2011-2012 ZDHS, the median age at first sex for women is 18.9 years of age versus 20.6 years for men. As indicated by the median age of marriage (19.7 years, women, 24.8 years, men), pre-marital sex is common in Zimbabwe (ZIMSTAT/ICF International 2012). Polygyny is not uncommon in Zimbabwe; 5 percent of married men are polygynous and 11 percent of women who are currently married have a husband with multiple wives (ZIMSTAT/ICF International 2012).

\section{Contraception and Fertility}

In Zimbabwe, fertility rates are significantly higher among rural women (4.8) than among urban women (3.1) (ZIMSTAT/ICF International, 2012). Mirroring data worldwide, contraceptive use increases with educational attainment and with the number of living children a woman has. According to the 2010-2011 ZDHS, 59 percent of all married women use a method of family planning. Nearly all use a modern method, while 1 percent of married women reported using a traditional method. The most commonly used methods among married women are the pill (41 percent) and injectables (8 percent). Use of condoms and implants is low, with only 3 percent of married women using each method; only 1 percent has been sterilised.

Use of modern contraception is higher among sexually-active women who are unmarried (62 percent) and there are differences in method mix between women who are and are not married. Condom use is much more prevalent among unmarried women (30 percent) than among those who are married ( 3 percent) and whereas 41 percent of married women use oral contraceptives, only 18 percent of unmarried sexually active women use the pill (ZIMSTAT/ICF International 2012).

\section{Family Planning: Commodities and User Fees}

The Zimbabwe National Family Planning Council (ZNFPC) is the main government body dealing with reproductive health. The ZNFPC was established by an act of Parliament as part of the MoHCW, to focus on: family planning, adolescent and sexual health, STIs, cervical cancer screening, fertility clinics, family planning/HIV integration (including HIV testing and counseling [HTC]), MMC, and PMTCT.

In terms of service coverage, according to the 2005 DHS, over 95 percent of Level 1 facilities reported providing oral contraceptives, Depo-Provera, and both male and female condoms; only 9 percent provided implants (CSO/Macro 2007). The majority (72.7 percent) of hospitals provides family planning services on a daily basis, although only 38.4 percent cater to youth.

Clinic-based programmes are complemented by community-based distribution programmes that provide counselling and referrals for family planning, as well as oral contraceptives, and 
male and female condoms. While there is some support for communication for family planning provided by PSI and other agencies, in recent years funding for such campaigns has been limited.

Logistics and supply remain a backbone of any programme to introduce or deliver health commodities. In Zimbabwe, JSI Deliver supports product storage and distribution of contraceptive commodities. According to a health facilities assessment report, male and female condoms and oral contraceptives were mostly in stock in the 30 days prior to the assessment (Osika et al. 2011). On average only 2.6 percent of Level 1 facilities reported stock-outs of male or female condoms and only 3.5 percent reported stock-outs of oral contraceptives. Depo-Provera was reported to be out of stock more in the mainly rural provinces, indicating that there might be challenges with supply to these areas. Matabeleland South province reported the highest proportion of facilities (22 percent) reporting stock-outs.

The ZNFPC charges user fees for products they distribute at the clinic level. Some organizations have expressed concern over this, as the commodities are given to ZNFPC for free. Overall, approximately one-third of Level 1 facilities charge user fees for family planning, with 33.3 percent charging for oral contraceptives and 36.8 percent for injectables. On average, 37 percent of the hospitals charge user fees for family planning services (Osika et al. 2011).

\section{Maternal and Child Health}

Zimbabwe has a relatively high rate of births attended by skilled providers as well as deliveries in health facilities. The 2010-2011 ZDHS indicated that 65 percent of live births in the five years prior to the survey occurred in a health facility and 66 percent were delivered by a skilled provider (ZIMSTAT/ICF International 2012). Antenatal services had been received by 90 percent of women who gave birth in the five years before the survey, although only 19 percent had services in their first trimester. Urban and rural women were equally likely to have received ANC from a health professional, though women with higher than a secondary education were more likely to have received services from a doctor (46 percent) than women with lower levels of education (1-11 percent). Postnatal services were less common, with only 27 percent of women and 12 percent of newborns receiving a check-up in the first two days after childbirth (ZIMSTAT/ICF International 2012).

Despite the access to ANC services and skilled providers, maternal mortality rates (MMR) are high in Zimbabwe, and have increased over the past 20 years from less than 300 deaths per 100,000 live births in 1999 to 960 deaths per 100,000 live births in 2011 (ZIMSTAT/ ICF International 2012). One of chief reasons for the high MMR in Zimbabwe is HIV and AIDS, which was found to have caused more than 25 percent of maternal deaths in a large 2007 survey (Munjaja et al. 2007).

A recent cohort study showed that female HIV incidence was very high during the first nine months after childbirth (5.7/100 women-years-at-risk), and that those women who knew that their partners had other sexual partners were about four times more likely to acquire HIV (Munjoma et al. 2010). This finding suggests the postpartum period may be a particularly important time and opportunity to reach women using new HIV prevention technologies or 
strategies, and that postpartum or infant care programmes should be considered as potential venues for pilot programmes for new prevention technologies. The relatively high proportion of births delivered in a health facility may provide an opportunity to encourage women to come for follow-up services, including making HIV prevention methods available.

\section{Sexually Transmitted Infections and HIV}

HIV infection is clustered among people with a history of STIs. According to the 2009 ANC Sentinel Surveillance Report, women who had genital ulcer disease (GUD) or a history of GUD were three times more likely to be HIV-positive than those who had never had GUD (Fraser et al. 2011). Data from the 2005-2006 ZDHS indicated that respondents who reported having an STI recently were significantly more likely to be HIV-positive; 40 percent of women reporting an STI were HIV infected compared to 24 percent who did not have an STI or STI symptoms. For men, 32 percent of those reporting an STI were HIV infected compared to 18 percent of STI uninfected males (Fraser et al. 2011). In the 2010-2011 ZDHS, 10 percent of women and 7 percent percent of men reported having an STI or symptoms of an STI in the 12 months preceding the survey (ZIMSTAT/ICF International 2012). Among women, 4 percent reported that they had an STI; 6 percent had a bad-smelling, abnormal discharge; and 5 percent had a genital sore or ulcer. Among men, 3 percent reported that they had an STI; 3 percent had a bad-smelling, abnormal discharge; and 4 percent had a genital sore or ulcer. Overall, 10 percent of women and 7 percent of men had either had an STI or symptoms of an STI. Overall, as shown in Figure 6, STI episodes recorded at public health facilities have been declining, however, recent reports suggest increased rates in some groups, such as youth (15-24 year olds) in Harare and mine workers in Mhondoro (Fraser et al. 2011).

STI prevention is now part of all HIV prevention programmes and has also been linked to other services like HTC, PMTCT, ART, and condom promotion. Yet STI activities are under-resourced and have lost visibility and support-maybe due to their inclusion as part of the HIV prevention programme.

Figure 6. Number of STI cases reported in health institutions per year (2000-2009)

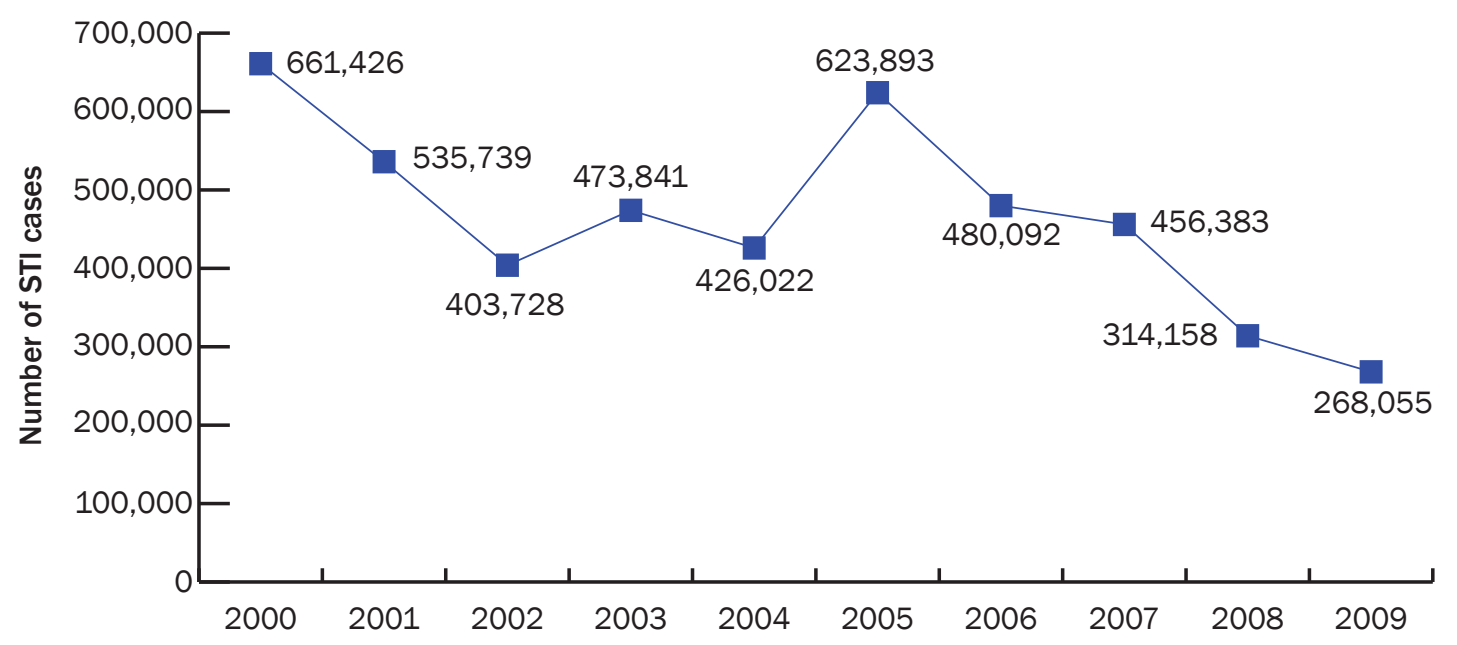

Source: Ministry of Health and Child Welfare NT5 2009 
The 2010-2011 ZDHS (ZIMSTAT and ICF International, 2012) found that prevalence of STIs or STI symptoms varied among women based on residence, education, and wealth. While women in rural areas were more likely than women in urban areas to have had an STI or STI symptoms, there was no substantial variation among men based on urban-rural residence. Among both women and men, prevalence of STIs and STI symptoms was higher among those who were divorced, separated, or widowed than among those who were married and those who had never been married but were sexually active. In terms of health seeking behaviour, nearly half of women and men who had an STI or STI symptoms sought advice or treatment from a clinic, hospital, private doctor, or other health professional. Men were more likely than women (11 percent and 3 percent, respectively) to seek treatment from a traditional healer or other source. Fifty-one percent of women and 43 percent of men did not seek any treatment when they had an STI or STI symptoms (ZIMSTAT/ICF International 2012).

\section{Cervical Cancer}

Zimbabwe faces a serious disease burden from cervical cancer and human papillomavirus (HPV), the STI that causes the majority of cases (Bruni et al. 2014); annual incidence of cervical cancer is more than twice as high in Zimbabwe (34.5 cases per 100,000 women) than the global average (15.1 per 100,000) and one-third higher than neighboring countries in East Africa (25.8 per 100,000). Cervical cancer is the third most common cause of cancer among women in the world, yet it is the main cause of cancer among Zimbabwean women (Bruni et al. 2014).

As is the case in most low- and middle-income countries, Zimbabwe has no mass cervical cancer screening programme (Mupepi et al. 2011). Pap smears, the most effective cervical cancer screening method, are not generally accessible and only 7 percent of women in Zimbabwe are screened annually (UNFPA 2011). Zimbabwean women tend to access cervical cancer screening when seeking Depo-Provera in family planning clinics or at hospital outpatient clinics if they have symptoms (Mupepi et al. 2011).

In an effort to develop simpler, less expensive techniques to enable widespread screening, Jhpiego conducted clinical trials of Visual Inspection using Acetic Acid (VIA), in which acetic acid is used to visualise the cervix in real time, without the need to send specimens to a laboratory (Jhpiego 2010). The Government of Zimbabwe (GoZ), with several other agencies, including UNFPA, is working on increasing access to VIA, which is now being implemented in 19 cervical cancer screening centres throughout the country (Bruni et al. 2014). In addition, the HPV vaccine was approved by the Zimbabwean regulatory authorities, but is not yet in widespread use (UNFPA 2011). Given that HPV has been linked with increased risk of HIV, cervical cancer screening programmes represent a potential opportunity for introducing ARVbased prevention methods for women. 


\section{POLICY RESPONSE}

Over the last 25 years, Zimbabwe has developed a policy environment for HIV prevention that has resulted in a multi-sectoral approach led by a national coordination authority and guided by evidence-informed strategic frameworks. Zimbabwe's national response to the HIV epidemic has been guided by the National Policy on HIV and AIDS, which was adopted in December 1999 through an Act of Parliament (Republic of Zimbabwe 1999). These overall policies are supplemented by various sector-level policies, strategies, and workplans that derive from emerging evidence. Starting in 1987, various plans have been developed, many of which emphasise the importance of prevention in Zimbabwe's response to HIV (see Table 2, page 16). Specific guidelines covering the range of standard and emerging biomedical interventions are based

Guidelines for Biomedical Interventions

- National Guidelines for HIV Testing and Counselling (2005)

- National TB Control Guidelines (2007)

- National Guidelines for HCT in Children (2008)

- National TB-HIV Guidelines (2009)

- National Community and Homebased Care Guidelines (2009)

- National PMTCT Protocols/Treatment Guidelines (2010)

on local evidence as well as international stan-

dards (see sidebar).

Zimbabwe's policy environment reflects the country's commitment to fulfill international and regional obligations related to HIV including the:

$\checkmark \mathrm{MDGs}^{1}$

- UN General Assembly Special Session on AIDS Declaration (2001) ${ }^{2}$

- Maseru Declaration (2011)

- Maputo Plan of Action on Sexual and Reproductive Health and Rights $(2011,2006)^{4}$

- Global Plan Towards Elimination of New HIV Infections in Children by 2015 and Keeping their Mothers Alive ${ }^{5}$

The strategy for the current Zimbabwe National HIV and AIDS Strategic Plan (ZNASP) 20112015 is driven by the NAC, and its implementation is spearheaded by the MoHCW. The priorities of the ZNASP 2011-2015 priorities are:

- Prevention of new HIV infections in adults and children, aiming to reduce the rate of annual infections by 50 percent by 2015 ;

- Reduction of mortality among PLHIV, aiming to reduce annual AIDS deaths by 38 percent by 2015 .

\footnotetext{
${ }^{1 \text { http://www.un.org/millenniumgoals/ }}$

${ }^{2}$ http://www.un.org/ga/aids/coverage/FinalDeclarationHIVAIDS.htm

${ }^{3}$ www.un.org/africa/osaa/reports/africa-regional-media-dialogue-june2011-maseru-declaration.pdf

${ }^{4}$ https://www.unfpa.org/africa/newdocs/maputo_eng.pdf

${ }^{5}$ http://www.unaids.org/en/media/unaids/contentassets/documents/unaidspublication/2011/

20110609_JC2137_Global-Plan-Elimination-HIV-Children_en.pdf
} 
Table 2: Policy, strategy, and programme support for key prevention interventions

\begin{tabular}{|c|c|c|}
\hline Partner reduction & Male circumcision & $\begin{array}{c}\text { Condom promotion and } \\
\text { distribution }\end{array}$ \\
\hline $\begin{array}{l}\text { Zimbabwe National AIDS } \\
\text { Strategic Plan 2006-10 }\end{array}$ & $\begin{array}{l}\text { Zimbabwe National AIDS } \\
\text { Strategic Plan 2006-10 }\end{array}$ & $\begin{array}{l}\text { Zimbabwe National AIDS } \\
\text { Strategic Plan 2006-10 }\end{array}$ \\
\hline $\begin{array}{l}\text { Addressed multiple parallel } \\
\text { partnerships as priority inter- } \\
\text { ventions on sexual behaviour } \\
\text { and norm change. }\end{array}$ & $\begin{array}{l}\text { Identified MC as a potential } \\
\text { service-based HIV prevention } \\
\text { intervention, paved the way } \\
\text { for acceptability and feasibil- } \\
\text { ity study. }\end{array}$ & $\begin{array}{l}\text { Condom distribution aimed } \\
\text { to make more widely avail- } \\
\text { able re-branded public } \\
\text { sector and socially marketed } \\
\text { condoms, particularly in rural } \\
\text { and remote areas. Targets } \\
\text { adults and couples who } \\
\text { either are not monogamous, } \\
\text { do not know their status, or } \\
\text { are HIV discordant. }\end{array}$ \\
\hline $\begin{array}{l}\text { National Behaviour Change } \\
\text { Strategy 2006-10 }\end{array}$ & $\begin{array}{l}\text { Male Circumcision Policy } \\
2009\end{array}$ & $\begin{array}{l}\text { National Behaviour Change } \\
\text { Strategy 2006-2010 }\end{array}$ \\
\hline $\begin{array}{l}\text { Three of six key themes } \\
\text { address multiple and con- } \\
\text { current partnerships and } \\
\text { partner reduction. }\end{array}$ & $\begin{array}{l}\text { Launched in } 2009 \text { "to } \\
\text { provide a framework for } \\
\text { provision of safe, accessible, } \\
\text { voluntary, and sustainable } \\
\text { male circumcision services } \\
\text { in a way that safeguards the } \\
\text { human rights of individuals } \\
\text { and communities." }\end{array}$ & $\begin{array}{l}\text { Notes importance of consis- } \\
\text { tent condom use, condom } \\
\text { promotion among youth, } \\
\text { and condom use in regular } \\
\text { relationships. }\end{array}$ \\
\hline $\begin{array}{l}\text { National Behaviour Change } \\
\text { Plan 2006-10 }\end{array}$ & $\begin{array}{l}\text { Male Circumcision Strategy } \\
2010\end{array}$ & $\begin{array}{l}\text { National Female Condom } \\
\text { Strategy 2006-2010 }\end{array}$ \\
\hline $\begin{array}{l}\text { Main aim is to promote HIV } \\
\text { testing and sexual risk reduc- } \\
\text { tion with partner reduction } \\
\text { and "faithfulness" as key } \\
\text { elements. }\end{array}$ & $\begin{array}{l}\text { Though a draft, MC interven- } \\
\text { tion started in } 4 \text { pilot sites. } \\
\text { Approximately } 10,000 \mathrm{MC} \\
\text { procedures performed by } \\
\text { August } 2010 \text { and govern- } \\
\text { ment indicated that all plans, } \\
\text { systems and tools in place to } \\
\text { allow rapid scale-up of MC. }\end{array}$ & $\begin{array}{l}\text { Provided framework and } \\
\text { demonstrated commitment } \\
\text { for Zimbabwe's distribution } \\
\text { of female condoms that } \\
\text { far exceeds that of most } \\
\text { countries. }\end{array}$ \\
\hline
\end{tabular}

\section{Programme Strategy and Implementation}

The primary support for HIV/AIDS programming is from the national AIDS levy, through which the Government of Zimbabwe deducts 3 percent from all employers and employees for a fund administered by NAC. NAC is the overall coordinating body for the ZNASP, while the Zimbabwe AIDS Network coordinates the civil society response. Faith- and community-based networks and organisations play an important role, and some have developed their own prevention strategies. The contribution of community-level organisations is well recognised, but the community response is poorly defined, insufficiently prioritised, and has been compromised by the economic crisis. Zimbabwe is also increasingly looking at policies to address broader structural factors that drive HIV risk. For example, the United States Centers for Disease Control 
and Prevention (CDC) is assisting Zimbabwe to develop an alcohol policy, indicating recognition of the role that alcohol use plays in driving risky behaviour and HIV incidence.

\section{Legal Frameworks and Context}

Zimbabwe's legal context serves to both support and weaken these HIV prevention policy efforts. Human rights are protected by the constitution and are addressed within the ZNASP. Zimbabwe has even passed legislation to help uphold the rights of "vulnerable" people, yet these efforts do not change the fact that homosexuality and sex work are illegal. The lack of legal status and protections presents obstacles to effective HIV prevention, treatment, care and support for sex workers and MSM (as well as IDUs and prison inmates). In addition to affecting the vulnerable populations directly, such laws and policies also have an impact on the sexual partners of MARPs. There is no mechanism to record, document, and address cases of discrimination experienced by PLHIV or any other vulnerable populations. There are also no independent national institutions for the promotion and protection of human rights that consider HIV-related issues within their purview, or any focal points within government departments to monitor HIV-related human rights abuses and discrimination. Despite the lack of legal frameworks for prevention activities with sex workers, prisoners, MSM, and IDUs, informal lobby groups for these populations have been allowed to exist in Zimbabwe.

Women's and girls' constitutional rights on protection and gender equality are hampered by the primacy of customary law over the Bill of Rights. Although the Constitution includes a clause that promotes gender equality, it undercuts fundamental values by recognising the primacy of customary law over the Bill of Rights. The 2011 Synthesis Report (Fraser et al. 2011) noted that customary laws governing marriage, divorce, and inheritance within the context of a patriarchal ideology, which sees women as minors, contributes to the vulnerability of women and girls.

\section{Policies that Can Make a Difference}

The 2011 Zimbabwe Analysis of HIV Epidemic, Response and Modes of Transmission Report (Fraser et al. 2011) was to be used as a platform to update the evidence base used to develop the Zimbabwe HIV and AIDS Strategic Plan 2011-2015. The report included a midterm review of the implementation of the ZNASP 2006-2010, as well as a secondary analysis of the 2005 ZDHS. The document outlined several areas where existing policies facilitate or hinder HIV prevention (see box, page 18), and where modifying these policies or pushing for implementation could have a significant impact. 


\section{Policies facilitating/hindering HIV prevention efforts}

\section{Facilitating}

The Prevention, Control, and Post-Exposure Prevention (PEP) policy (2007)

Domestic Violence Act of 2007 [Chapter 5:16]

- Sexual Offences Act of 2001 [Chapter 9:21]

\section{Hindering}

National Guidelines for HCT in Children (2008)

- The Prevention, Control, and Post-Exposure Prevention (PEP) policy (2007) aims to reduce HIV-related risk, morbidity, and mortality among health workers, victims of sexual abuse, and people at risk of accidental exposure to HIV infection. However, converting these guidelines into accessible services for women and girls who have been raped has been slow, and comprehensive post-rape services are still limited. The MoHCW has made some progress by introducing clinical guidelines for post-rape care, and UNFPA, IOM, UNICEF, and other NGOs are in the process of establishing pilot onestop centres.

- The Domestic Violence Act, passed in 2007, is not realizing its potential to curb domestic violence due to slow and incomplete implementation. Domestic violence continues, along with abuse originating from cultural or customary rites or practices that discriminate or degrade women, such as virginity testing and female genital mutilation.

- Although the Sexual Offences Act (2001) criminalises HIV transmission in marriage, lack of awareness and knowledge among women, the rigid justice system, and entrenched socio-cultural barriers hinder full implementation.

- The HIV testing policy does not allow a sexually active girl under 18 years of age to have an HIV test without her parents' or guardian's consent, which limits access to critical services for young women who are at high risk of infection.

- The legal age of consent for marriage is 16 years, while the legal age to access services without parental or guardian consent of majority is 18 years. 


\section{HIV PREVENTION}

As outlined above, prevention of new infections is a key strategy in the 2011-2015 ZNASP, and was the first of four key strategies within the 2006-2010 ZNASP, which promoted "refocusing and intensifying behaviour change approaches and programmes." The National Behavioural Change Strategy for Prevention of Sexual Transmission of HIV 2006-2010 was a multisectoral framework to reduce sexual transmission of HIV by promoting responsible sexual behaviour. The strategy recognises the key role of community leaders, the importance of clear and consistent messaging, and provision of adequate services for PLHIV. The National Behavioural Change Strategy has been rolled out to all 62 districts of the country after first operating in 26 districts. National coordination is done by UNFPA in collaboration with NAC, and implementation at district level is done by eight NGOs contracted by UNFPA. The involvement of traditional, opinion, and political leaders and faith-based organizations promotes open dialogue on risky behaviours and cultural practices, such as "dry sex," that fuel HIV transmission.

\section{Knowledge about HIV and AIDS}

HIV prevention activities have resulted in high levels of knowledge and awareness among the population regarding HIV and AIDS. According to the 2010-2011 ZDHS, 98 percent of men and women had some knowledge of HIV prevention methods, with men in rural areas (84 percent) having the lowest knowledge level (ZIMSTAT/ICF International, 2012). By the end of 2009, 81 percent of women and 82 percent of men aged 15-49 years knew that consistent use of condoms is a means of preventing the spread of HIV. Ninety percent of women and 91 percent of men in this age group knew that limiting sexual intercourse to mutually monogamous, uninfected partner can reduce the chances of contracting HIV.

Women and men residing in urban areas are somewhat more likely to be knowledgeable about HIV prevention methods than their rural counterparts. Higher educational attainment is also positively associated with increased awareness of HIV prevention methods for both women and men. Compared to women (82 percent) and men (83 percent) who are divorced, separated, or widowed, women ( 66 percent) and men ( 68 percent) who have never been married and never had sex are less likely to know that using condoms and limiting sexual intercourse to one uninfected partner reduces the risk of HIV transmission.

\section{HIV Testing}

HIV testing and counselling has evolved from largely urban-based voluntary counselling and testing (VCT) to nationwide PICT. Zimbabwe's MoHCW introduced PICT in 2007, the same year that the WHO issued its guidelines recommending that countries with generalised epidemics offer HTC to everyone presenting at all healthcare institutions (Sibanda et al. 2012). By the end of 2009, there were more than 500 VCT service delivery points integrated with health services (502) and managed by NGOs (27) as well as some 1,000 counselling and referral-only service delivery points (Osika et al 2011). HTC services are provided through mobile outreach, workplace programmes, and family planning clinics. As indicated in Table 3 , a high proportion of Level 1 health facilities provide PICT and VCT. 
According to the 2010-2011 ZDHS, a comparable percentage of men (88 percent) and women (91 percent) reported knowing where to get an HIV, yet considerably more women (60 percent) than men (39 percent) had ever been tested for HIV (ZIMSTAT/ICF International 2012). Additionally, 34 percent of women versus only 20 percent of men reported having an HIV test and receiving the results in the year prior to the survey (ZIMSTAT/ICF International 2012). Young women aged 15-24 were much more likely than young men of the same age to have been tested for HIV and to have received the results in the year prior to the survey (45 percent and 24 percent, respectively). HIV testing coverage increased dramatically between the 2005-06 and 2010-11 ZDHS among both men (63 percent to 69 percent) and women (from 76 percent to 80 percent) who were tested and received the results. Despite the uptake in HIV testing, the evidence on the behavioural consequences of HTC is mixed. According to the 2005-06 ZDHS, couples are generally uninformed about whether their partners have other partners. Most couples do not seem to share the results of their tests with each other, and disagreement about whether each partner has disclosed their status is common (CSO/ Macro 2007).

With the advent of the WHO guidelines suggesting initiating treatment at a CD4 count of 350, NAC has encouraged people to go for re-testing so that they may be put on ARV treatment (NAC 2013). While data on re-testing is minimal, programme experience and estimates suggest an increase in testing and re-testing among people who have previously tested HIV negative, as well as an increase in men testing and re-testing voluntarily. Both have been attributed to increased access to ART medication. Further analysis of these clients and programmes may provide insights for structuring the testing and re-testing that will be needed for ARV-based prevention implementation. Although tenofovir gel might create a burden for the already taxed HIV testing programme, it might also give providers something to offer women who test negative, and potentially attract women to HCT services.

Table 3: Proportion of primary care facilities providing HIV diagnostic services, largely rapid testing and ELISA, per province (2012)

\begin{tabular}{|l|r|r|r|c|}
\hline Province & $\begin{array}{c}\text { Level 1 } \\
\text { facilities (\#) }\end{array}$ & PICT \% & VCT \% & $\begin{array}{c}\text { Screen HIV for TB } \\
\text { patients \% }\end{array}$ \\
\hline Bulawayo & 19 & 100.0 & 100.0 & 94.7 \\
\hline Harare & 52 & 84.6 & 76.9 & 75.0 \\
\hline Manicaland & 216 & 94.4 & 97.7 & 86.6 \\
\hline Mashonaland Central & 111 & 100.0 & 99.1 & 93.7 \\
\hline Mashonaland East & 168 & 100.0 & 100.0 & 94.0 \\
\hline Mashonaland West & 141 & 98.6 & 95.7 & 86.5 \\
\hline Masvingo & 162 & 95.7 & 96.3 & 87.0 \\
\hline Matabeleland North & 92 & 93.5 & 95.7 & 92.4 \\
\hline Matabeleland South & 108 & 99.1 & 98.1 & 88.9 \\
\hline Midlands & 181 & 95.0 & 96.1 & 87.8 \\
\hline National coverage & $\mathbf{1 , 2 5 0}$ & $\mathbf{9 6 . 4}$ & $\mathbf{9 6 . 6}$ & $\mathbf{8 8 . 7}$ \\
\hline
\end{tabular}

Source: Osika et al. 2011 


\section{Male Condoms: Distribution and Use}

A key objective of the 2006-2010 ZNASP was to make both re-branded public sector and socially marketed condoms more widely available in rural and remote areas. Male condom distribution almost doubled from 2000 to 2008 (see Figure 7), attributed to strong social marketing initiatives and the distribution infrastructure from the national to village levels. The strong distribution infrastructure was developed, with a reported zero stock-out rate for condoms, under JSI's Delivery Team Top-Up (DTTU) system (JSI 2014) and PSI's social marketing efforts (PSI 2014). The more recent decline has been linked to the contraction of the retail and wholesale sector during the economic crisis (Fraser et al. 2011). Although condom distribution has increased, overall, the 95.5 million condoms distributed in 2008 represent only two-thirds of the ZNASP 2011-2015 annual 150 million target (Fraser et al. 2011).

Data from a number of studies provide information about condom use in different populations and contexts. According to the 2010-2011 ZDHS, condom use rates are relatively high (females, 48 percent; males, 74 percent) during high-risk sex, which is defined as sex with a non-marital, non-cohabiting partner (ZIMSTAT/ICF International 2012), whereas condom use tends to be much less common (females, 3.6 percent; males, 7.7 percent) with regular partners (Fraser et al. 2011). For both women and men, those who reported using a condom at last sex within the 12 months prior to the survey, were more likely to be HIV-positive; 41 percent of women and 19 percent of men reporting condom use at last sex were HIV-positive compared to 15 percent of women and 14 percent of men who did not use a condom at last sex. One hypothesis for this pattern is that HIV-positive respondents may have been more likely to have used condoms because they either knew or suspected they were HIV-positive and use condoms to prevent transmission, rather than to avoid being infected (ZIMSTAT/ICF International 2012). Therefore, a microbicide could fill the substantial gap for HIV-negative women who use no protection against HIV, yet are at risk.

Figure 7. Male condom distribution by sector (2000-2009)

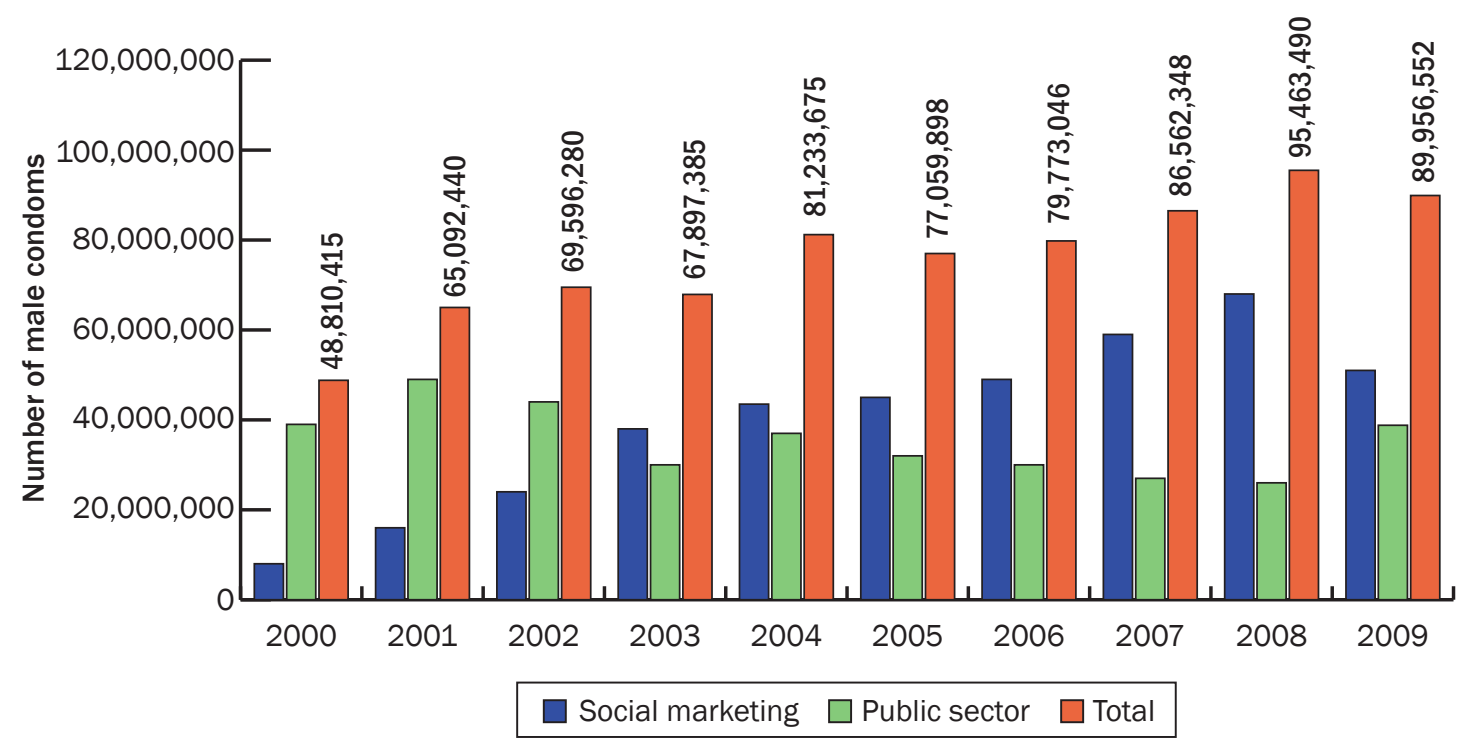

Source: Ministry of Health and Child Welfare AIDS and TB Programme 


\section{Female Condom Availability}

In Zimbabwe, female condom promotion and distribution efforts are led by the MoHCW, the ZNFPC, and PSI. Female condoms are sold through pharmacies, hair salons, barber shops, sex worker networks, and support groups for PLHIV. From 2004-2007, Care brand female condom distribution increased by 150 percent and public sector distribution tripled (CHANGE 2009). The 2006-2010 National Female Condom Strategy had forecasted female condom consumption of $14,055,004$ by the end of 2010 , which was surpassed with distribution and consumption of 15,426,325 female condoms between 2006 and 2009 (Figure 8). Despite the need to involve the formal health system to manage HIV testing, monitoring, and regulatory issues, Zimbabwe's relatively successful female condom programme could provide important insights for introducing new prevention technologies, such as tenofovir gel, for women. These lessons will be mediated by the need to involve the health system in delivering ARV-based products.

Figure 8. Female condom distribution in Zimbabwe (2000-2009)

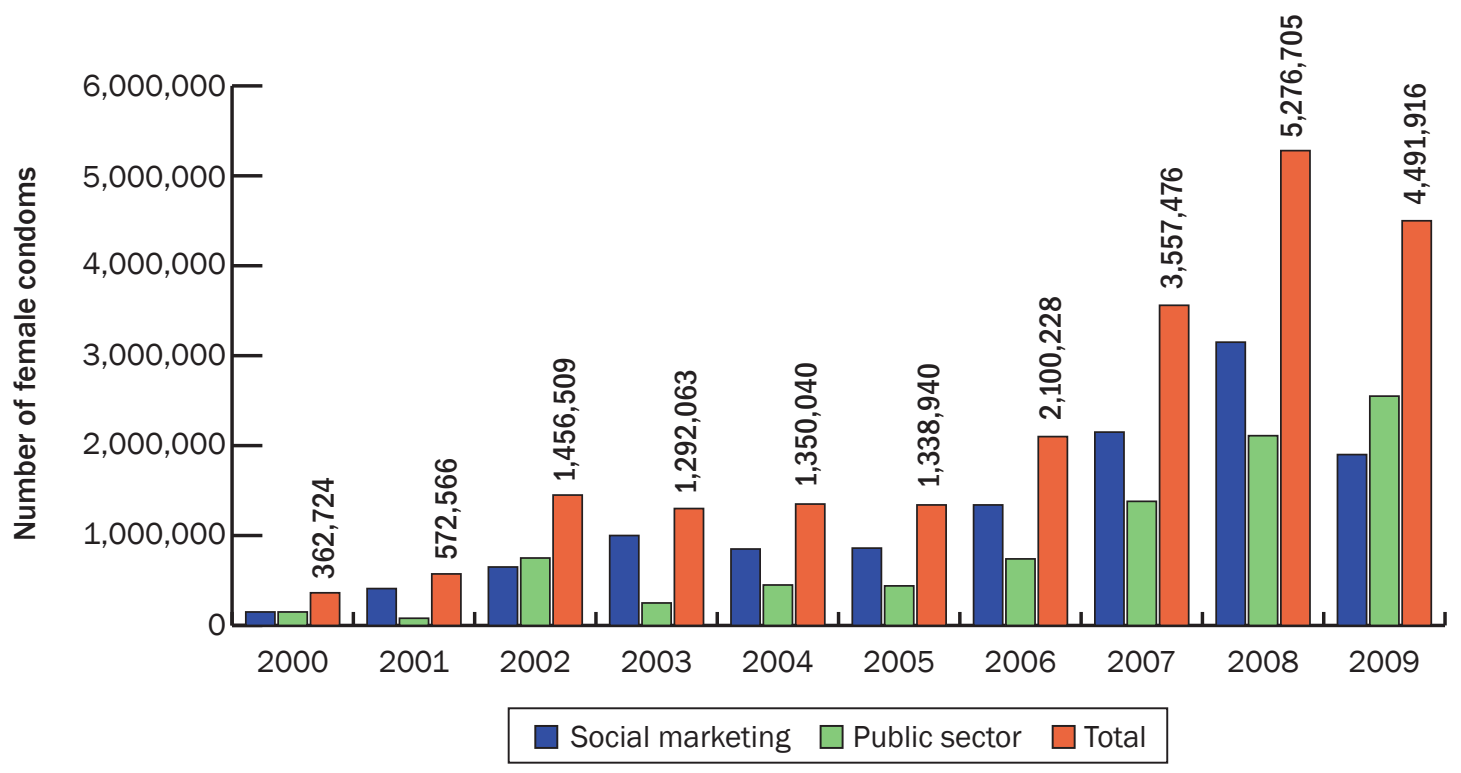

Source: Ministry of Health and Child Welfare AIDS and TB Programme

Source: In Fraser et al. 2011

\section{Prevention of Mother-to-Child Transmission (PMTCT)}

In 2010, Zimbabwe adopted the WHO's new guidelines on PMTCT, which recommended that HIV-positive pregnant women in need of treatment for their own health be given lifelong access to ART, and that those who were not in need of treatment be given short-term ARV prophylaxis to prevent MTCT. Notably, the WHO 2010 guidelines were the first to recommend that women could take ARVs during breastfeeding (WHO 2010). By 2011, 78 percent of HIV-infected pregnant women received ARVs for PMTCT and between 2009 and 2011, there was a 45 percent decline in the number of new paediatric HIV infections, from 17,700 to 9,700 (IATT 2012). HIV testing rates among pregnant women tripled between 2005 (29 per- 
cent) and 2010 (90 percent), with the estimated proportion of HIV positive pregnant women receiving ARVs for PMTCT increasing from 84 percent in 2010 to 98 percent in 2011 (IATT 2012; UNAIDS 2012). The successful scale up of the PMTCT programme in Zimbabwe could provide important lessons for the introduction of ARV-based prevention for women. In particular, the public/private partnerships among local and international organizations could serve as a potential model for service delivery implemented by the public sector with support and technical assistance from the private sector.

\section{Male Circumcision}

As one of 13 countries with high HIV prevalence in the general population and low rates of male circumcision, Zimbabwe was prioritised by UNAIDS and WHO for scaling up voluntary medical male circumcision (VMMC) services (AIDSTAR 2014). When the policy was implemented in 2007, the goal was to increase the prevalence of circumcised males (15-49 years old) from 10 percent to 80 percent by 2015 (AIDSTAR 2014). According to the NAC, the number of men undergoing VMMC more than doubled in one year from 40,755 in 2012 to 90,000 in 2013 (NAC 2014) and the proportion of MC clients agreeing to HCT has been as high as 98 percent (WHO/UNAIDS 2010).

Currently, as a key partner in Zimbabwe's national programme, PSI/Zimbabwe offers VMMC services at fixed sites and through outreach and mobile services in 35 districts, circumcising about 10,000 men and adolescents every month (PSI/Zimbabwe 2014). PSI/Zimbabwe reaches adolescents primarily during school holiday campaigns and adult males at workplace programmes (PSI Zimbabwe 2014). Such public health demand creation activities-community dialogues, interpersonal communication sessions, edutainment, mass media, and use of public personalities as role models-are all potential strategies for generating demand for ARV-based prevention for women.

\section{Post-Exposure Prophylaxis}

As part of its strategy to reduce HIV incidence by 50 percent in 2015, the NAC included expanding access to post-exposure prophylaxis from less than 10 percent of health facilities to 100 percent by 2015 in the ZNASP II (NAC 2011). In particular, although health workers are likely to be aware of PEP and access it when needed, the ZNASP emphasised scaling up access to those most in need, home-based care givers and victims of rape and sexual assault (NAC 2011). Indeed, the low rate of scale-up and access to PEP -an existing, efficacious HIV prevention strategy-could be indicative of some of the hurdles that might be faced when introducing tenofovir gel. 


\section{HIV TREATMENT}

The number of Zimbabweans on ART has nearly doubled from 300,000 in 2010 to over 500,000 in 2012 (NAC 2012; UNAIDS 2013). This ART uptake has been attributed to decentralization of treatment programmes, especially in areas funded by the Global Fund (Fraser et al. 2011). Although 85 percent of those currently qualifying for ART based on the WHO's 2010 guidelines (initiating ART at a CD4 count of 350 instead of 200), over 115,000 PLHIV are still on a waiting list to start treatment (UNAIDS 2013; NAC 2012). While the Government of Zimbabwe has been successful in raising funds for ARV drugs themselves, particularly from donors like the Global Fund, the current level of funding is not sufficient for supporting ART programmes. Another hindrance to the goal of achieving access to ART through all public health facilities is the lack of doctors available, since current guidelines stipulate that only MDs can initiate ART (NAC 2012). In order to avoid similar barriers to ART access, it will be important when tenofovir gel or other ARV-based prevention methods for women are introduced that guidelines enable provision by a broader cadre of healthcare workers and programmes are designed in a decentralised manner from the outset. 


\section{HEALTH SYSTEMS/SERVICE DELIVERY}

Zimbabwe's health system includes and is influenced by the government, the private sector, donors, neighboring countries, religious and faith-based institutions, as well as the communities and users of the health facilities (Osika et al. 2011). Government health services are divided into four levels of care:

- Primary care facilities, typically run by a nurse or nurses, offer primarily preventive, maternity or curative services provided by health workers and community-based distributors. Primary care facilities are administered by community, ward and rural health committees and supervised by the District Health Office (DHO).

- Secondary care facilities are the lowest level facility where patients can see a medical doctor and include district hospitals, as well as some missionary and private facilities. Patients are generally referred to secondary facilities from primary care, although for some difficult issues, patients are referred to tertiary care. District hospitals general serve a catchment area of 140,000 people and, as they are often the closest facility, provide primary care, as well. District hospitals are administered by a hospital and district health committee and are supervised by DHOs, which are, in turn, supervised by the Provincial Medical Directorate (PMD).

- Tertiary care consists of the seven provincial hospitals in all provinces, except Bulawayo and Harare that have central hospitals, instead. Tertiary facilities have more specialists to treat more complicated cases, although due to high rates of migration out of Zimbabwe during the recent economic decline, tertiary facilities may not have experienced specialists and rely on junior doctors who are not equipped to manage difficult cases.

- Quarternary care is comprised of the six central hospitals in Bulawayo, Harare, and Chitungwiza. The central hospitals report directly to the $\mathrm{MoH}$ and have the most advanced equipment, staff and specialists, and pharmaceuticals to deal with the most severe cases.

Although Zimbabwe's health care system is structured for patients to first present at primary care facilities and then access subsequent levels of care via referrals, numerous patients seek primary care at all facility levels due to geographical convenience and because they perceive that primary care facilities are less equipped to provide services adequately. Because patients seek primary care at all facility levels, it would be beneficial to consider delivering tenofovir gel at various care levels in high HIV prevalence areas. 


\section{HIV EXPENDITURE IN ZIMBABWE}

HIVIAIDS expenditure from 2006 to 2009 varied between US\$86 million in 2006 to a low of US $\$ 26.5$ million in 2008 before increasing again to US $\$ 54$ million in 2009 (Fraser et al. 2011). The increase from US $\$ 26.5$ million in 2008 to US $\$ 54$ million in 2009 can be attributed largely to the relative stabilisation of the economy, as well as the introduction of the multi-currency system which halted hyper-inflation. International contributions for HIV and AIDS also increased sharply from approximately US $\$ 54$ million in 2009 to US $\$ 114$ million in 2010, reflecting large infusions of support for ART programmes. During this time, the proportion of total HIVIAIDS spending for prevention decreased from 39 percent in 2006 to 22 percent in 2009, again reflecting the shift of resources and programme emphasis to treatment roll-out. Of the 2009 expenditure for prevention, over 40 percent was spent on PMTCT activities; about 17 percent on communication for social and behaviour change; and about 15 percent on VCT activities (Fraser et al. 2011).

Both domestic and international sources of support have enabled Zimbabwe to fund its HIV and AIDS response. The GoZ raised funds mainly through the NATF, a 3 percent levy collected from taxable income in all sectors to mitigate the impact of HIV and AIDS. These funds are channelled directly to NAC by the Ministry of Finance. NATF contributed approximately US $\$ 5$ million in 2009 , US $\$ 20.5$ million in 2010 , and US $\$ 26.5$ million in 2011 towards HIV programmes. About 50 percent of NATF funds were used for procurement of ARVs, while the remainder supported other HIV programmes as well as administration and coordination.

Given that the economic climate in Zimbabwe is not likely to improve significantly in the next several years, it is likely that the government will be unable to finance introduction of tenofovir gel. Therefore, at least initially, external agencies will be critical for supporting the cost of both programming and subsidizing the product. 


\section{LOOKING AHEAD}

Zimbabwe has shown tremendous leadership in reducing the impact of HIV and AIDS by quickly embracing international guidelines based on scientific evidence and creating national policies. Despite the serious economic decline and the deterioration of basic health services, Zimbabwe has scaled up a number of prevention programmes by creating successful public/private partnerships. The most notable examples_PMTCT, PICT, and VMMC_- can inform strategies to deliver tenofovir gel and other ARV-based prevention methods when they become available.

Zimbabwe's medical professionals have also shown leadership by being involved in the clinical testing of new products and regimens such as VIA and treatment as prevention. Zimbabwe has made significant contributions to microbicide development for over two decades through numerous clinical trials conducted in the country.

Zimbabwe can build on its policy and scientific capacity to determine if tenofovir gel offers added benefits relative to costs within the evolving context of HIV prevention interventions. If Zimbabwe's leaders consider tenofovir gel to be a useful addition to the existing HIV prevention landscape, introduction research will be needed to determine the most strategic entry points for introduction. In particular, given the likelihood that the Government will continue to rely on external support, it would be useful to begin developing partnerships to test different service delivery models, and to begin fundraising now for such projects.

One of the main obstacles to broad access of HIV prevention commodities is likely to be the limited intersection between HIV and family planning services. Strengthening the links between ANC and HIV preventative services, as has been done for PMTCT programmes, will be an important strategy for reaching HIV negative pregnant women at risk of HIV infection. Even if ARV-based products are not yet licensed for pregnant or breastfeeding women, providing information and establishing relationships with women in the postpartum period could provide an important opportunity for prevention in this high risk group.

Zimbabwe's momentum in curbing the HIV epidemic, experience with new technologies and clinical trials, and its capacity for operations research, makes it a conducive setting for designing and conducting the necessary demonstration projects and initial planning and protocol development can begin now. 


\section{REFERENCES}

Abdool, Karim Q, et al. 2010. "Effectiveness and safety of tenofovir gel, an antiretroviral microbicide, for the prevention of HIV infection in women," Science 329(5996):1168-1174. DOI:10.1126/science.1193748.

AIDSTAR. 2014. "Potential cost and impact of expanding male circumcision in Zimbabwe." http://www.aidstar-one.com/sites/default/files/resources/external/health_policy_initiative/Zimbabwe_11209.pdf Accessed 21 March 2014.

amFAR. "Achieving an AIDS-free generation for gay men and other MSM in Southern Africa," Country Profile: Zimbabwe. http://www.amfar.org/uploadedFiles/_amfarorg/Articles/Around_The_World/GMT/2013/MSM percent20Country percent20Profiles percent20Zimbabwe percent20092613.pdf. Accessed 20 February 2014.

Bruni, L. et al. 2014. "Human papillomavirus and related diseases in Zimbabwe," Summary Report 2014-0303. ICO Information Centre on HPV and Cancer (HPV Information Centre). http://www.hpvcentre.net/statistics/reports/ZWE.pdf. Accessed 7 March 2014.

Central Statistical Office (CSO) [Zimbabwe] and Macro International Inc. 2007. Zimbabwe Demographic and Health Survey 2005-2006. Calverton, Maryland, USA: CSO and Macro International Inc.

Center for Health and Gender Equity (CHANGE). 2009. "Female condoms: Lessons from Zimbabwe," Country Profile. Washington, DC: CHANGE. http://www.genderhealth.org/files/uploads/change/publications/zimbabwecountryprofile.pdf Accessed 24 March 2014.

Cowan, F. et al. 2012. "HIV prevalence and incidence amongst sex workers remains high in Zimbabwe (Abstract MOPE345)," poster exhibition, XIX International AIDS Conference, Washington, DC, 22-27 July. http://respondentdrivensampling.wordpress.com/2012/07/23/hiv-prevalence-and-incidence-amongst-sexworkers-remains-high-in-zimbabwe. Accessed 21 February 2014.

Decosas, J. and N. Padian. 2002. "The profile and texts of the epidemics of sexually transmitted infections including HIV in Zimbabwe,” Sexually Transmitted Infections 78(1): i40-i46. doi:10.1136/sti.78.suppl_1.i40

Domestic Violence Act. 2007. Chapter 5:16, Act No. 24 of 2006. Published in Government Gazette, 26th February 2007.

Dube, S. et al. 2013. "Policy and programme considerations for ARV-based prevention for women: Insights from key opinion leaders in Zimbabwe about tenofovir gel," Report. New York and Johannesburg: Population Council.

Elizabeth Glaser Pediatric AIDS Foundation (EGPAF). 2014. “Country spotlight: Zimbabwe.” http://www. pedaids.org/countries/zimbabwe. Accessed 21 March 2014.

Fraser, N. et al. 2011. "Zimbabwe analysis of HIV epidemic, response and modes of transmission." Harare: Zimbabwe National AIDS Council. http://ms-hiv-gdc.org/wp-content/uploads/group-documents/1/1314808832-Zimbabwesynthesisreport.pdf. Accessed 21 March 2014.

Gregson, S. et al. 2013. "Evidence for a contribution of the community response to HIV decline in eastern Zimbabwe?” AIDS Care 25(Suppl 1): S88-S96. doi:10.1080/09540121.2012.748171

Gregson, S. et al. 2010. "HIV decline due to reductions in risky sex in Zimbabwe. Evidence from a comprehensive epidemiological review," International Journal of Epidemiology 39(5): 1311-1323. doi:10.1093.

Halperin, D. T. et al. 2011. "A surprising prevention success: Why did the HIV epidemic decline in Zimbabwe?" PLoS Med 8(2):e1000414. doi:10.1371/journal.pmed.1000414

Hargrove, J. W. et al. 2011. "Declining HIV prevalence and incidence in perinatal women in Harare, Zimbabwe," Epidemics 3(2): 88-94. doi: 10.1016/j.epidem.2011.02.004

Interagency Task Team (IATT) on the Prevention and Treatment of HIV Infection in Pregnancy Women, Mothers, and Children. 2012. "From countdown to zero," Fact sheet. http://www.emtct-iatt.org/wp-content/ uploads/2012/10/PMTCT-Factsheet-Zimbabwe.pdf Accessed 21 March 2014. 
ICF Macro. 2011. Zimbabwe Demographic and Health Survey [ZDHS] 2010-11 Preliminary Report. Zimbabwe National Statistics Agency and MEASURE DHS. Calverton, Maryland, USA: ICF Macro. www.measuredhs.com/ pubs/pdf/PR6/PR6.pdf Accessed 24 March 2014.

Jhpiego. “Cervical cancer prevention and treatment." http://www.jhpiego.org/content/cervical-cancer-prevention-and-treatment Accessed 20 March 2014.

JSI. “Delivery team topping up: Bringing about reliable distribution in difficult environments." http://www. jsi.com/JSIInternet/Features/article/display.cfm?thisSection=Features\&thisSectionTitle=Features\&thisPage=stories\&ctid=1030\&cid=267\&tid=20\&id=396. Accessed 5 March 2014.

Lewis, J. J. et al. 2005. "Beer halls as a focus for HIV prevention activities in rural Zimbabwe," Sexually Transmitted Diseases 32: 364-369. PMID: 15912083.

Matambo, R. et al. 2006. "Voluntary counseling and testing by nurse counselors: what is the role of routine repeated testing after a negative result?” Clinical Infectious Diseases 42(4): 569-571.

Ministry of Health and Child Welfare (MoHCW), Zimbabwe and NAC. 2009. "National behaviour change strategy for prevention of sexual transmission of HIV," Baseline Survey. Harare: MoHCW.

Muchini, B. et al. 2011. "Local perceptions of the forms, timing and causes of behavior change in response to the AIDS epidemic in Zimbabwe," AIDS and Behavior 15(2): 487-498.

Munjaja, S. et al. 2007. "Maternal and perinatal mortality study." Harare: Ministry of Health and Child Welfare.

Munjoma, M. W. et al. 2010. "The incidence of HIV among women recruited during late pregnancy and followed up for six years after childbirth in Zimbabwe," BMC Public Health 10: 668. doi:10.1186/1471-2458-10-668.

Mupepi, S. C., C. M. Sampselle, and T. R. B. Johnson. 2011. "Knowledge, attitudes, and demographic factors influencing cervical cancer screening behavior of Zimbabwean women," Journal of Women's Health 20(6). doi:10.1089/jwh.2010.2062

National AIDS Council (NAC). 2014. "Male circumcision in Zimbabwe.” http://www.nac.org.zw/category/tags/ male-circumcision-zimbabwe. Accessed 21 March 2014.

NAC. 2012. "National ARV uptake doubles." http://www.nac.org.zw/news/national-arv-uptake-doubles Accessed 21 March 2014.

—. 2011. Zimbabwe National HIV and AIDS Strategic Plan (ZNASP) 2011-2015. http://www.nac.org.zw/ sites/default/files/Zimbabwe-National-HIV-AIDS-Strategic-2011-2015-Plan.pdf. Accessed 21 March 2014.

- 2006. National Behavioural Change Strategy for Prevention of Sexual Transmission of HIV 2006-2010. www.nac.org.zw/sites/default/files/Behaviour-Change-programme.pdf Accessed 26 March 2014.

Nyamayemombe, C. et al. 2010. "The association between violence against women and HIV: Evidence from a national population-based survey in Zimbabwe," Zimbabwe Working Papers, No.4. Calverton, Maryland, USA: ICF Macro.

Osika, J. et al. 2011. “Zimbabwe health system assessment 2010.” Bethesda, MD: Health Systems 20/20 Project, Abt Associates Inc.

Population Council. 2014. "Setting the stage for ARV-based prevention for women: a snapshot of the Zimbabwean context," Program Brief. Johannesburg, South Africa, and New York: Population Council.

Population Council. 2012. “A toolkit for strategic decisionmaking and planning for microbicides." New York: Population Council.

PSI Zimbabwe. “Condom social marketing.” http://www.psi.org/zimbabwe Accessed 5 March 2014.

—. Zimbabwe Country Program. http://www.psi.org/zimbabwe Accessed 10 March 2014. 
Republic of Zimbabwe. 1999. National Policy on HIV/AIDS for Zimbabwe. http://www.youth-policy.com/Policies/Zimbabwe_National_Policy_on_HIV_AIDS.cfm?ignore\&r=A1714223881 Accessed 20 March 2014.

. National HIV/AIDS and Tuberculosis Control Programmes. National Guidelines for TB/HIV co-management. http://www.who.int/hiv/pub/guidelines/zimbabwe.pdf Accessed 21 March 2014.

Sibanda, E. L. et al. 2012. "An assessment of the Zimbabwe Ministry of Health and Child Welfare provider initiated HIV testing and counselling programme," BMC Health Services Research 12:131ff.

Singh, S., et al. 2000. "Gender differences in the timing of first intercourse: Data from 14 countries," International Family Planning Perspectives 26(1): 21-28, 43.

UNAIDS. 2013. “Global report: UNAIDS report on the global AIDS epidemic 2013.” Geneva: UNAIDS. Revised and reissued, November 2013.

_ 2012. “Global AIDS response progress report," Zimbabwe Country Report. http://www.unaids.org/ en/dataanalysis/knowyourresponse/countryprogressreports/2012countries/ce_ZW_Narrative_Report.pdf Accessed 24 March 2014.

United Nations. 2014. “Millennium development goals and beyond 2015." http://www.un.org/millenniumgoals/ Accessed 17 March 2014.

UNFPA. 2011. Country Programme Action Plan (CPAP) 2012-2015 for the Programme of Cooperation Between The Government of the Republic of Zimbabwe and The United Nations Population Fund. http:// countryoffice.unfpa.org/zimbabwe/?publications=7253 Accessed 20 March 2014.

WHO. 2010. "New guidance on prevention of mother-to-child transmission of HIV and infant feeding in the context of HIV." http://www.who.int/hiv/pub/mtct/PMTCTfactsheet/en/. Accessed 21 March 2014.

WHO/UNAIDS. 2010. "Scaling-up male circumcision programmes in the Eastern and Southern Africa Region. Country update meeting to share lessons, explore opportunities and overcome challenges to scale-up," $A$ sub-regional consultation; Arusha, Tanzania; 8-10 June 2010. http://www.who.int/hiv/pub/malecircumcision/country_progress_meeting_report_jun10.pdf Accessed 21 March 2014.

ZimPAS, U.S. Embassy Public Affairs Section. 2012. "U.S. backs Zim on alcohol policy to curb HIV transmission." http://harare.usembassy.gov/cdc_alcohol_policy.html Accessed 21 March 2014.

Zimbabwe National Statistics Agency (ZIMSTAT) and ICF International. 2012. Demographic and Health Survey [DHS] 2010-11. Calverton, Maryland: ZIMSTAT and ICF International. 



\section{Population Council}

One Dag Hammarskjold Plaza

9th Floor

New York, New York 10017

www.popcouncil.org 